\title{
Impact of Interspecific Introgression on Anthocyanin Profiles of Southern Highbush Blueberry
}

\author{
Gad G. Yousef \\ Plants for Human Health Institute, Department of Horticultural Science and Department of Food \\ Bioprocessing and Nutrition Sciences, North Carolina Research Campus, North Carolina State \\ University, 600 Laureate Way, Kannapolis, NC 28081
}

Mary A. Lila

Plants for Human Health Institute, Department of Food Bioprocessing and Nutrition Sciences, North Carolina Research Campus, North Carolina State University, 600 Laureate Way, Kannapolis, NC 28081

\begin{abstract}
Ivette Guzman
Plants for Human Health Institute, Department of Horticultural Science, North Carolina Research Campus, North Carolina State University, 600 Laureate Way, Kannapolis, NC 28081

James R. Ballington

Department of Horticultural Science, North Carolina State University, 260 Kilgore Hall, Raleigh, NC 27695
\end{abstract}

\begin{abstract}
Allan F. Brown ${ }^{1}$
Plants for Human Health Institute, Department of Horticultural Science, North Carolina Research Campus, North Carolina State University, 600 Laureate Way, Kannapolis, NC 28081
\end{abstract}

AdDitional INDEX words. breeding population, HPLC, polyploidy, rabbiteye, Vaccinium corymbosum, V. angustifolium, $V$. darrowii, $V$. virgatum

\begin{abstract}
Blueberry (Vaccinium L. section Cyanococcus Gray), a rich source of polyphenolics with important implications for human health and chronic diseases, has become a major fruit commodity in the United States. This study was designed to assess the impact of introgression through interspecific hybridization on anthocyanin (ANC) profiles among blueberry species. Southern highbush blueberry ( $V$. corymbosum L.) and rabbiteye blueberry ( $V$. virgatum Ait.) commercial cultivars, North Carolina blueberry breeding selections, and blueberry breeding populations with varying degrees of introgression from multiple species were used to address this question. The breeding selections and populations were created and selected for traits not directly related to their ANC profiles and are therefore likely representative of the current selection objectives of most public and private breeding programs. Ripe fruit at a uniform stage of maturity were evaluated for ANC concentration and profile in 2 consecutive years (2010 and 2011) from all plants. Total ANC ranged from 189 to 464, 74 to 421 , and 227 to $537 \mathrm{mg} / 100 \mathrm{~g}$ (frozen fruit) in the commercial cultivars, breeding selections, and breeding populations, respectively. Significant increases in total ANC were observed among material that represents an expanded gene pool in southern highbush blueberry (introgression from $V$. angustifolium Ait., $V$. elliottii Chap., $V$. myrsinites Lam., $V$. pallidum Ait., $V$. tenellum Ait., $V$. fuscatum Ait., $V$. constablaei Gray, and $V$. arboreum Mar.). Differences in acylation and glycosylation patterns were also observed in the same material, which may condition relative stability, absorption, and bioavailability of ANC. Results suggest that the expansion of the gene base through interspecific hybridization can have both a positive and negative impact on ANC accumulation and that breeders need to be aware of these issues early in the breeding program.
\end{abstract}

What the consumer calls blueberry is the fruit of three distinct species within the genus Vaccinium section (or sub-genus) Cyanococcus (Ericaceae family) (Galletta and Ballington, 1996; Kalt et al., 2001). Vaccinium angustifolium [lowbush blueberry

Received for publication 23 Sept. 2013. Accepted for publication 11 Dec. 2013. Funding for this study was provided by the University of North Carolina General Administration Special Allocation for Collaborative Research at the North Carolina Research Campus, NC.

We thank the North Carolina Blueberry Council for funds provided to support this study. The North Carolina Department of Agriculture, Piedmont Research Station, Salisbury, NC, is greatly appreciated for continuous field and plant maintenance.

${ }^{1}$ Corresponding author. E-mail: afbrown2@ncsu.edu.
(LBB), $2 n=4 x=48]$ is native to eastern and central Canada and the northeastern United States. It has a distinct appearance and low growth habit, generally no more than $40 \mathrm{~cm}$ tall. Vaccinium virgatum (previously $V$. ashei Reade) [rabbiteye blueberry (REB) $2 n=6 x=72]$ is a hexaploid native to the southeastern United States and gains its name from the distinctive pink color of the berry fruit before maturity. Vaccinium corymbosum [northern highbush blueberry (NHB), $2 n=4 x=48$ ] was domesticated less than a century ago in New Jersey and includes the principal cultivars grown in northern climates (Ballington, 2009; Chavez and Lyrene, 2009). The southern highbush blueberry (SHB, $2 \mathrm{n}=4 \mathrm{x}=48$ ) cultivars were developed from 
hybridizations among the $V$. corymbosum and other Vaccinium species possessing southern U.S. adaptation attributes such as lower chilling requirements, early ripening, and greater tolerance to high summer temperatures compared with NHB (Ballington, 2009; Galletta and Ballington, 1996; Stringer et al., 2013).

Interspecific hybridization has played a significant role in blueberry improvement and has been used extensively to combine useful traits from the three species in the primary gene pool ( $V$. corymbosum, $V$. angustifolium, and $V$. virgatum) and (increasingly) to transfer unique genes or chromosomal segments (introgressions) from the secondary gene pool (non-cultivated Cyanococcus species) (Ballington, 2009; Brevis et al., 2008). However, blueberry is intolerant of inbreeding and most new cultivars are the result of one or more hybridizations or are selections of open-pollinated clones. The result is that many new cultivars contain significant genomic introgressions from one or more wild relatives. Of particular importance to commercial production in the southern United States and California has been the hybridization and selection of progenies that represent significant introgression of native southern species such as $V$. virgatum and $V$. darrowii Camp into the genetic background of $V$. corymbosum for adaptation to higher temperatures and shorter vernalization periods (Ballington, 2001; Sharpe, 1954; Stringer et al., 2013). Additional species including $V$. elliottii, $V$. constablaei, $V$. tenellum, and $V$. simulatum Small are also being introduced into SHB germplasm through several public and private breeding programs to produce material with even greater adaptation or disease resistance than what is currently available in the primary gene pool (Brevis et al., 2008). Barriers against the "triploid block" (infertility of $3 \times$ genotypes) have been overcome by using unreduced gametes of diploid and hexaploid crosses and through the creation of pentaploid $(5 \times)$ cultivars by crossing REB (6×) with NHB (4×) in releases such as 'Pearl River' and 'Robeson' (Ballington and Rooks, 2009; Spiers et al., 1996; Tsuda et al., 2013).

Over the past decade and a half, blueberry has become a major fruit commodity in the United States with a total annual production of $234,500 \mathrm{Mg}$ valued at $\$ 880$ million in 2011 (U.S. Department of Agriculture, 2013). Driving what represents an almost 3-fold increase in consumption and production is in large part an increased public awareness of the impact of dietary blueberry on human health (Basu et al., 2010; Blanck et al., 2008; DeFuria et al., 2009; Gonzales-Gallego et al., 2010; Martineau et al., 2006; Stull et al., 2010). Although blueberry contains an array of compounds that may contribute to health (e.g., organic acids, vitamins, proanthocyanidins, stilbenes, and phenolic acids), the primary focus of nutritional and medical research has been on anthocyanins (Grace et al., 2009; Johnson et al., 2013; Manach et al., 2005; Prior et al., 2001; Rimando et al., 2004).

The ANC profile of blueberry is relatively unique among fruit crops in that it contains appreciable levels of five conjugated aglycones (delphinidin, cyanidin, petunidin, peonidin, and malvidin) that can be further modified through glycosylation or acylation. The aglycones can be conjugated with galactose, glucose, or arabinose. Bioavailability and bioactivity of these compounds (as observed through in vitro and in vivo models) are influenced by both dosage and by the structural differences among the conjugated groups (Manach et al., 2005; McGhie and Walton, 2007; Prior and Wu, 2006; Yi et al., 2006). Acylation of ANC, for example, can positively influence the stability in a food but can attenuate the absorbance post-ingestion
(Charron et al., 2009). The overall accumulation and retention of ANC vary according to genotype, environment, stage of maturity, and post-harvest handling practices (Charles et al., 2012; Connor et al., 2002; Gustafson et al., 2012; Kalt et al., 2001; Prior et al., 1998; Reyes-Carmona et al., 2005; Scalzo et al., 2013).

Currently, no public or private breeding program (that we are aware of) is selecting for new blueberry cultivars primarily on the basis of ANC content or profile. Previous surveys of released material have identified variability in ANC among cultivated species (Connor et al., 2002; Kalt et al., 2001, 2008; Wang et al., 2012; Yousef et al., 2013), but the impact of introgressing significant genomic segments from wild Vaccinium species through interspecific hybridization has not been examined. By using the blueberry commercial cultivars, breeding selections, and breeding populations of a current public breeding program that focuses intensively on interspecific hybridization, we address this issue with the current research. The blueberry plant materials described in this article were selected for traits not directly related to ANC content and therefore are likely representative of what is occurring in other programs that also use similar germplasm. This is particularly relevant at a time when concerns have been raised about the potential genetic dilution of nutritionally important compounds as an unintended consequence of breeding for yield or adaptation (Davis, 2009).

\section{Materials and Methods}

Plant materials. Blueberry genotypes used in this study contained commercial cultivars, breeding selections (clones), and breeding populations (cross progenies). The commercial cultivars included eight REB (6×) cultivars (Columbus, Ira, Montgomery, Onslow, Powderblue, Premier, Tifblue, and Yadkin), seven SHB (4×) cultivars (Arlen, Legacy, Lenoir, O'Neal, Ozarkblue, Pamlico, and Sampson), and one pentaploid $(5 \times)$ cultivar, Robeson. With the exception of 'O'Neal' (which contains $12.5 \% \mathrm{~V}$. tenellum), the SHB pedigrees include genomic contributions from the species $V$. corymbosum, $V$. darrowii, and $V$. virgatum [in varying degrees, reported in percentages (Appendix A)], and are representative of the currently available SHB cultivars.

Breeding selections (13 replicated clones) and breeding populations ( 23 crosses, a total of 906 progenies) represent an expanded gene pool through broader introgression of wild species that include: $V$. angustifolium, $V$. elliottii, $V$. myrsinites, $V$. pallidum, $V$. tenellum, $V$. fuscatum, $V$. constablaei, and $V$. arboreum, in addition to the genetic contributions from $V$. corymbosum, $V$. darrowii, and $V$. virgatum that are also found in the commercial cultivars. The replicated clones included: $\mathrm{NC}$ 3961, NC 4263, NC 4365, NC 4385, NC 4398, NC 4900, SA10:135 (NC 4399), SA-13:75 (NC 4807), SA-4:2 (NC 4563), SHF2B1-20:21 (NC 5018), SHF2B1-21:3 (NC 5021), SHF2B1-25:25 (NC 5042), and SHF2B1-25:41 (NC 5043).

The breeding populations consisted of varying numbers of progeny generated from the following crosses: 'Arlen' $\times$ 'Georgia Gem' (74 plants), CHID2-14:73 $\times$ open-pollinated (OP) (28 plants), NC $1223 \times$ 'Columbus' (90 plants), NC $2873 \times$ OP (11 plants), NC $2898 \times$ G-615 (37 plants), NC $3147 \times$ 'Legacy' (six plants), NC $3147 \times \mathrm{NC} 4562$ (two plants), NC $3252 \times \mathrm{OP}$ (six plants), NC $3958 \times$ OP (40 plants), NC $4165 \times$ OP (six plants), NC $4295 \times$ 'Arlen' (34 plants), NC $4297 \times$ 'Ozarkblue' (69 plants), NC $4299 \times$ 'Ozarkblue' (164 plants), NC 4302 
$\times$ 'Georgia Gem' (two plants), NC $4302 \times$ 'Sunshine Blue' (nine plants), NC $4562 \times \mathrm{NC} 3476$ (31 plants), NC $4562 \times \mathrm{NC}$ 4179 (47 plants), NC $4562 \times$ NC 4361 (50 plants), NC $4812 \times$ OP (33 plants), NC 81-10-2 $\times$ 'Columbus' (69 plants), NJ 89-158-24 $\times$ 'Columbus' (37 plants), 'Reveille' $\times$ NC 3476 (55 plants), and 'Reveille' $\times$ NC 3920 (six plants). Detailed pedigree information (ploidy levels, origin, and species) for the commercial cultivars, breeding selections, and breeding populations are presented in Appendix A. Breeding selections and populations were created and selected for traits not directly related to their ANC profiles and are therefore likely representative of the current selection objectives of most public and private breeding programs (e.g., yield and adaptation).

Field EXPERIMENTAL TRIALS AND SAMPLE PREPARATION. Blueberry plants were established and maintained through North Carolina State University's (NCSU) blueberry breeding program. Two-year-old seedlings grown and maintained in a greenhouse (NCSU, Raleigh, NC) were transported to the field of Piedmont Research Station, Salisbury, NC, 2 weeks before transplanting. The seedlings were transplanted in bed rows $(60 \mathrm{~cm}$ apart) with drip irrigation and plastic mulch cover in Dec. 2006. The commercial cultivars and breeding selections (clones) were replicated a minimum of three times per genotype. Populations were composed of single-plant progenies from two heterozygous parents. Standard fertilization [14 kg nitrogen $(\mathrm{N})$ in April and $7 \mathrm{~kg} \mathrm{~N}$ in June] and pest control were followed. When plants were 6 and 7 years of age, fully ripe fruit were harvested at a uniform stage of maturity (when $75 \%$ of berries on any plant were fully ripe) and from comparable locations on each plant in Summer 2010 and 2011, respectively. Care was taken to avoid harvesting any visibly overripe fruit based on color and firmness. In both years, fruit were harvested once from each plant per season where the harvest season started from 28 May to 21 July 2010 and 1 June to 27 July 2011. Approximately $500 \mathrm{~g}$ of fruit was collected and packed on ice. Fruit were transported to the adjacent laboratory at the Plants for Human Health Institute, NC Research Campus, NCSU, Kannapolis, NC. After transport, fruit were frozen in liquid nitrogen and stored at $-80^{\circ} \mathrm{C}$ until they could be lyophilized and analyzed. Average fruit weight and diameter were measured using randomly selected subsets of each sample. Fruit were lyophilized before extraction using a freeze dryer (VirTis 24Dx48; SP Scientific, Stone Ridge, NY) with a temperature-controlled chamber for samples. Freeze-dried fruit were then stored at $-80{ }^{\circ} \mathrm{C}$ until extraction as described below. Weights of samples were taken before and after lyophilization to estimate dry matter (DM) content in the fruit.

ANTHOCYANIN EXTRACTION AND QUANTIFICATION. For each plant, 2.5 to $3.0 \mathrm{~g}$ of lyophilized tissues was extracted with $30 \mathrm{~mL}$ of $0.3 \%$ acetic acid in $\mathrm{MeOH}: \mathrm{H}_{2} \mathrm{O}(70: 30, \mathrm{v}: \mathrm{v})$ to compensate for the water removed in the freeze-drying process, stabilize ANC during extraction, and improve extraction efficiency. Extraction efficiency for ANC was enhanced by grinding tissues in a high-speed grinder for $2 \mathrm{~min}$ before extraction. Ground contents were transferred into $50-\mathrm{mL}$ tubes and vortexed for $5 \mathrm{~s}$ before centrifugation at $3400 \mathrm{~g}_{\mathrm{n}}$ for $15 \mathrm{~min}$ at $20{ }^{\circ} \mathrm{C}$, and then supernatants were decanted into $100-\mathrm{mL}$ volumetric flasks. The extraction was repeated two more times, collecting supernatants into the corresponding flasks and the final volume was brought to a $100 \mathrm{~mL}$ with the same extraction solvent. Extracts were immediately filtered into $2-\mathrm{mL}$ amber vials using $0.2-\mu \mathrm{m}$ polytetrafluoroethylene syringe filters (Fisher Scientific, Pittsburgh, PA).
Filtered samples were injected $(10 \mu \mathrm{L})$ into a high-performance liquid chromatography system (1200; Agilent Technologies, Santa Clara, CA) equipped with an ultraviolet-visible spectrophotometry diode array detector, controlled-temperature autosampler $\left(4{ }^{\circ} \mathrm{C}\right)$, and column compartment $\left(30^{\circ} \mathrm{C}\right)$. Chemstation software (Agilent Technologies) was used as the system run controller and for data processing. ANC separation and quantification were performed using a reversed-phase column $[250 \mathrm{~mm} \times 4.6 \mathrm{~mm} \times$ $5 \mu \mathrm{m}$ (Supelcosil LC-18; Supelco, Bellefonte, PA)] following the protocol described in Yousef et al. (2013). Briefly, the mobile phase consisted of $5 \%$ formic acid in $\mathrm{H}_{2} \mathrm{O}(\mathrm{A})$ and $100 \%$ methanol (B). A step gradient of 10\%, 15\%, 20\%, 25\%, 30\%, $60 \%, 60 \%, 10 \%$, and $10 \%$ of solvent B at $0,5,15,20,25,35,36$, 37 , and $40 \mathrm{~min}$, respectively, at a constant flow rate of $1 \mathrm{~mL} \cdot \mathrm{min}^{-1}$ was applied for samples and ANC commercial standards. Individual ANC compounds in samples were quantified as cyanidin 3-O-glucoside equivalents (milligrams per gram dry fruit tissue). Compounds were quantified using a standard curve of peak areas at $520 \mathrm{~nm}$, the maximum wavelength absorption for ANC, and the known injected concentrations for standards. To facilitate comparison with published data, ANC concentrations in this study were converted back to a frozen fruit basis and presented as milligrams per $100 \mathrm{~g}$ frozen fruit.

Statistical analysis. Analysis of variance (ANOVA) was performed using the general linear model procedure (PROC GLM) with random effects to estimate variation associated with the genotype, environment, and genotype $\times$ environment interaction using SAS software (Version 9.2 for Windows; SAS Institute, Cary, NC). For the commercial cultivars and breeding selections (replicated plants), the statistical model used was $\mathrm{y}_{\mathrm{ijkl}}=\mu+\mathrm{G}_{\mathrm{i}}+\mathrm{Y}_{\mathrm{j}}+\mathrm{P}_{\mathrm{k}}+\mathrm{R}(\mathrm{E})_{(\mathrm{j}) 1}+\mathrm{GY}_{\mathrm{ij}}+\varepsilon_{(\mathrm{ijkl})}[1]$; where $\mathrm{y}=$ response from the experimental unit, $\mu=$ overall mean, $\mathrm{G}=$ genotype (cultivar or clone), $\mathrm{Y}=$ year, $\mathrm{P}=$ plant, $\mathrm{R}(\mathrm{Y})=$ replication within year, GY $=$ genotype $\times$ year interaction effect, and $\varepsilon=$ experimental random error. For the breeding populations (with single plant genotypes within a population), the model used was $\mathrm{y}_{\mathrm{ijk}}=\mu+\mathrm{G}_{\mathrm{i}}+\mathrm{Y}_{\mathrm{j}}+\mathrm{P}(\mathrm{G})_{(\mathrm{i}) \mathrm{k}}+\mathrm{GY}_{\mathrm{ij}}+\varepsilon_{(\mathrm{ijk})}$ [2]; where $y=$ response from the experimental unit, $\mu=$ overall mean, $\mathrm{G}=$ cross, $\mathrm{Y}=$ year, $\mathrm{P}(\mathrm{G})$ = plant within cross, $\mathrm{GY}=$ cross $\times$ year interaction effect, and $\varepsilon=$ random error. Because the $\mathrm{G} \times \mathrm{Y}$ interaction for commercial cultivars, clones, and populations was significant, the $\mathrm{G} \times \mathrm{Y}$ mean squares were used as the error term to test genotype and year effects instead of the raw error term in the ANOVA. The PROC MEANS statement was used to compute genotype means, SDS, and ranges for ANC data (milligrams per $100 \mathrm{~g}$ frozen fruit) for the 2 years (2010 and 2011) separately. The ANC data were examined for normal distribution using the PROC UNIVARIATE NORMAL PLOT procedure.

To facilitate the comparison of the subclasses among genotypes, concentrations (milligrams per $100 \mathrm{~g}$ ) were expressed as percentages of total ANC per genotype. Percentages of the ANC subclasses were calculated and statistically analyzed for mean separation to assess the differences in percent of ANC subclasses (aglycone, glycoside, and acylated ANC in blueberry). Mean separations were performed by using LSMEANS statement and Tukey's honest significant test with the statistical models listed previously. The commercial cultivars and breeding selections (with replicated plants) were treated as one group to contrast southern highbush $(4 \times)$ with rabbiteye $(6 \times)$ blueberry genotypes using model [1]. The breeding populations (cross progenies) were treated as one separate group to test population 
performance for ANC accumulation and profile using model [2]. For the mean separation analyses, absolute values of total ANC (milligrams per $100 \mathrm{~g}$ frozen fruit) but percentages of ANC subclasses were used with both groups (commercial cultivars and breeding selections) and (breeding populations).

All possible correlations among traits (ANC content, fruit size, and harvest date) were calculated (PROC CORR procedure with SAS software) using Pearson's correlation to evaluate the relationship among total ANC, ANC subclasses, and fruit characteristics. The correlation analysis was conducted using the data from commercial cultivars and breeding selections combined as one group of genotypes that were evaluated in replicates and therefore can provide meaningful correlation coefficients $(r)$. All data of ANC and ANC subclasses used for correlation analysis were the absolute values (milligrams per $100 \mathrm{~g}$ frozen fruit).

\section{Results}

Anthocyanin Classification. A total of 18 ANC compounds were identified and assayed in the blueberry plants including: 1) delphinidin-3-O-galactoside; 2) delphinidin-3-O-glucoside; 3) cyanidin-3-O-galactoside; 4) delphinidin-3-O-arabinoside; 5) cyanidin-3-O-glucoside; 6) cyanidin-3-O-arabinoside; 7) petunidin-3-O-galactoside; 8) petunidin-3-O-glucoside; 9) peonidin-3-O-galactoside; 10$)$ petunidin-3-O-arabinoside; 11) malvidin-3-O-galactoside; 12) malvidin-3-O-glucoside; 13) malvidin-3-O-arabinoside; 14$)$ delphinidin-3-O-(6" acetyl)glucoside; 15$)$ cyanidin-3- $O-\left(6^{\prime \prime}\right.$-acetyl)glucoside; 16) malvidin-3-O-(6" -acetyl)galactoside; 17$)$ petunidin-3-O(6"-acetyl)glucoside; and 18) malvidin-3-O-(6" -acetyl)glucoside (Fig. 1). In all subsequent tables ANC data are presented as:
1) total ANC (milligrams per $100 \mathrm{~g}$ frozen fruit); 2) percentage of ANC sharing the same aglycone [delphinidin (delp-ANC), cyanidin (cyan-ANC), petunidin (petu-ANC), peonidin (peonANC), or malvidin (malv-ANC)]; 3) percentage of ANC with the same pattern of glycosylation [(galactose (gala-ANC), glucose (gluc-ANC), or arabinose (arab-ANC)]; and 4) percentage of ANC that is acylated [acyl-ANC (compounds 14 through 18 in Fig. 1)]. On average (across the commercial cultivars, breeding selections, and breeding populations), the principle ANC found were modified aglycones of malvidin $(38 \%)$ followed by similarly modified aglycones of delphinidin (28\%), cyanidin $(17 \%)$, petunidin $(12 \%)$, and peonidin $(3 \%)$. Based on glycosylation pattern, the average ANC subclasses constituted $46 \%$, $32 \%$, and $18 \%$ for galactose-, arabinose-, and glucose-based ANC, respectively. On average, the acylated ANC constituted only $3 \%$ of the total ANC across all blueberry plants evaluated in this study.

Source of variation. Three analyses of variance for commercial cultivars, breeding selections (clones), and breeding populations (crosses) were conducted for total ANC, subclasses of ANC, and fruit characteristics (Table 1). Both year and genotype were significant sources of variation for total ANC among commercial cultivars, breeding selections, and populations. The year contributed a greater percentage of variation among commercial cultivars and breeding selections, and genotype was a greater source of variation among populations. A significant genotype $\times$ year interaction was noted but contributed a relatively minor proportion of variation in all three analyses. With cultivars and breeding selections, no significant variation was detected among plants of the same genotype. As would be expected of unreplicated, segregating populations, however, significant plant-to-plant variation was observed within populations.

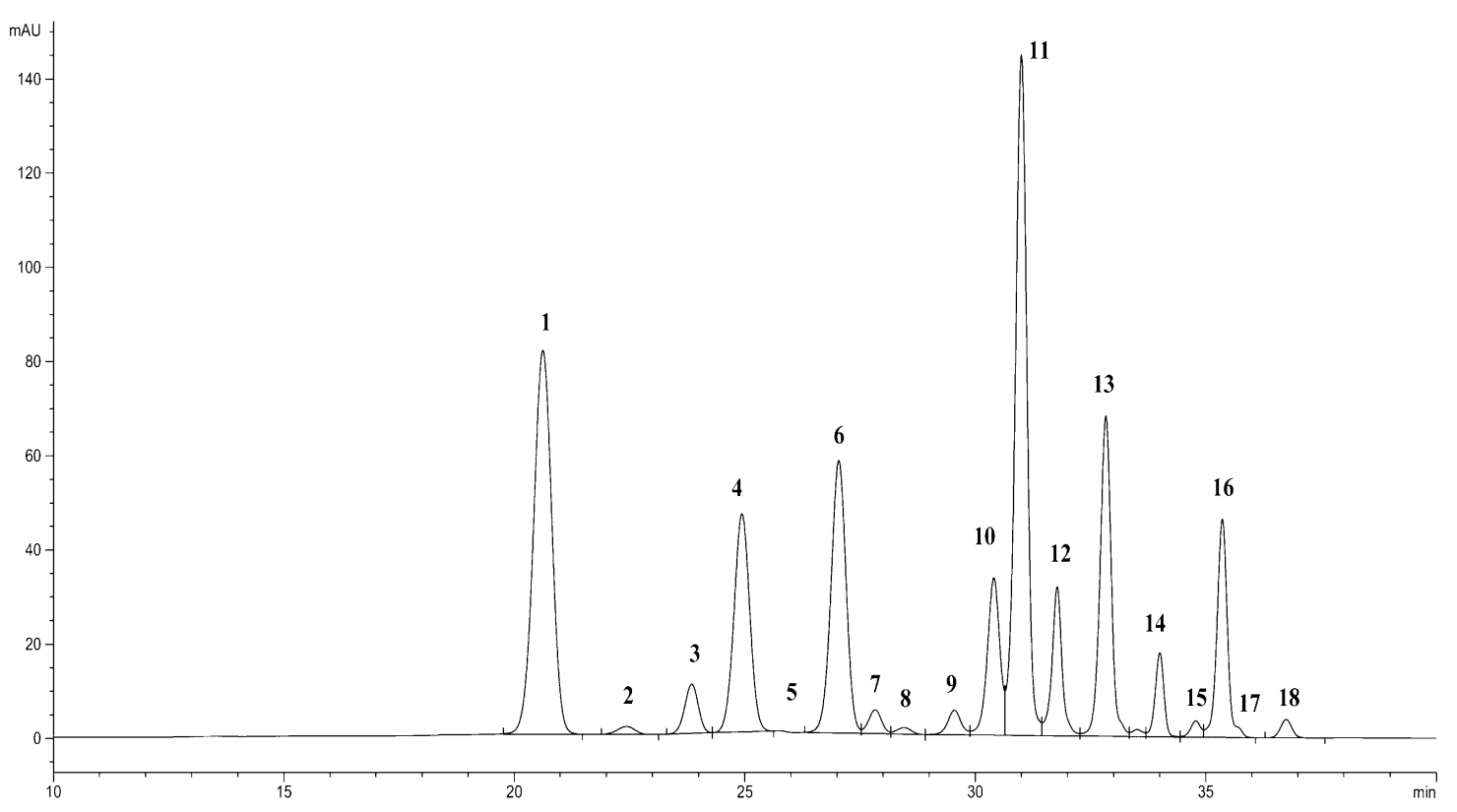

Fig. 1. Representative high-performance liquid chromatography (HPLC) chromatogram showing individual anthocyanins measured in the commercial blueberry cultivar Arlen in 2011 at Salisbury, NC. Anthocyanin peak identification: 1) delphinidin-3-O-galactoside; 2) delphinidin-3- $O$-glucoside; 3) cyanidin-3- $O$ galactoside; 4) delphinidin-3-O-arabinoside; 5) cyanidin-3-O-glucoside; 6) cyanidin-3-O-arabinoside; 7) petunidin-3-O-galactoside; 8) petunidin-3-O-glucoside; 9) peonidin-3-O-galactoside; 10) petunidin-3-O-arabinoside; 11) malvidin-3- $O$-galactoside; 12) malvidin-3-O-glucoside; 13) malvidin-3-O-arabinoside; 14$)$ delphenidin-3-O-(6" -acetyl)glucoside; 15) cyanidin-3-O-(6" -acetyl)glucoside; 16) malvidin-3-O-(6"-acetyl)galactoside; 17) petunidin-3- $O$-(6" -acetyl)glucoside; and 18) malvidin-3-O-(6"-acetyl)glucoside. Compounds detected using HPLC system with diode array detector at a wavelength of $520 \mathrm{~nm}$. 


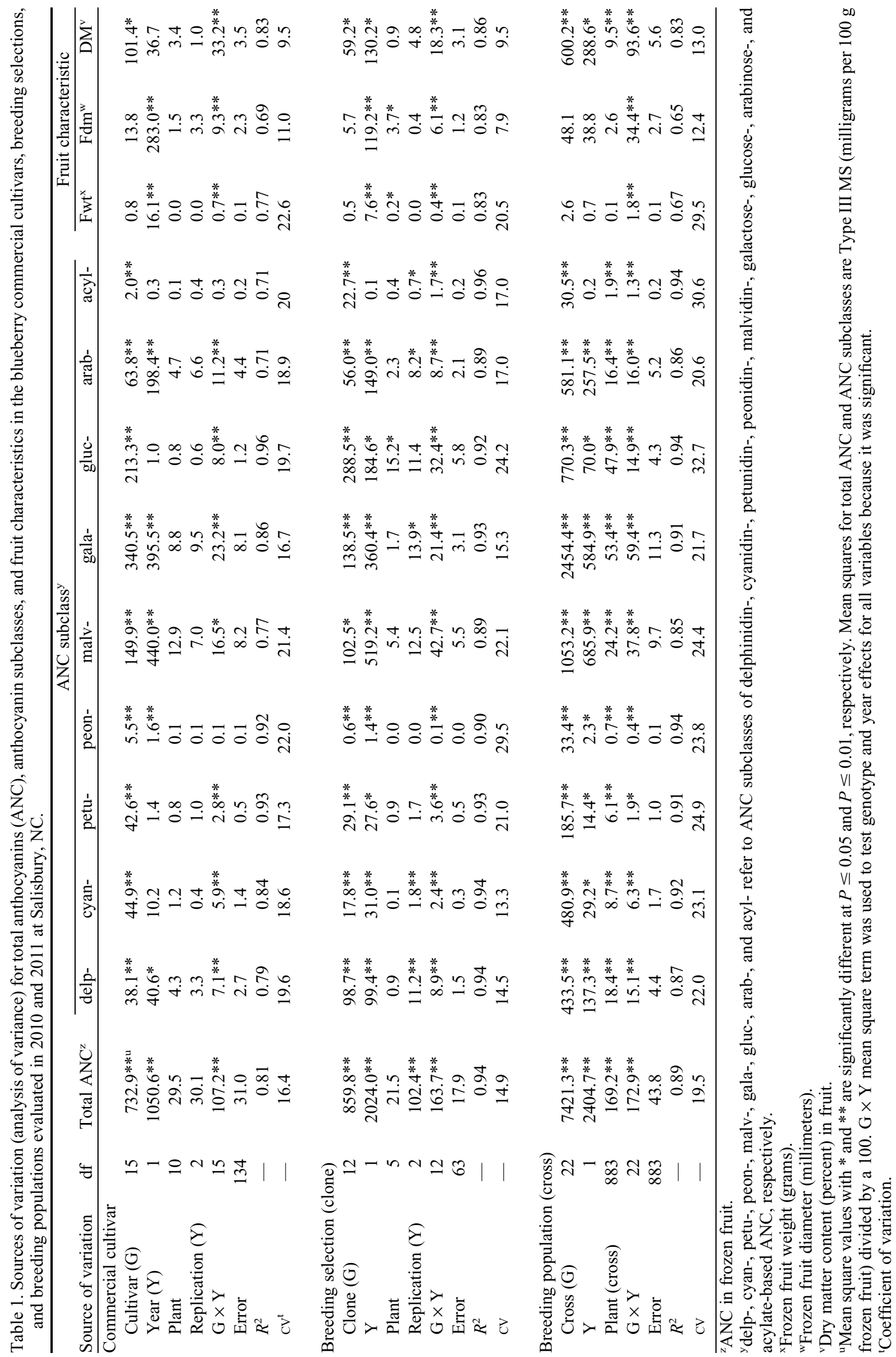


Interesting differences were observed with variance estimates among the ANC subclasses. Although cultivar and year were significant sources of variation for all aglycone subclasses, the relative proportion of these variances was quite different. Year and genotype effects were of similar magnitude in respect to delp-ANC among cultivars and selections but the year effect explained a far greater proportion (up to five times) of the variance associated with malv-ANC. Differences were also observed with cyan-ANC, petu-ANC, and peon-ANC, but these differences were not consistent between the analysis of cultivars and selections. Across the segregating populations, genotype was the principle source of variation, but the relative importance of genotype and year was strikingly different, with year effects having a far greater impact on malv-ANC than any of the other aglycone subclasses. As was observed with total ANC, the $\mathrm{G} \times \mathrm{Y}$ interaction was significant but explained a relatively minor proportion of the variance.

The ANOVA of the glycosylated subclasses in cultivars and selections also revealed interesting differences. Although both genotype and year were significant sources of variation in cultivars and selections, the relative importance of these sources was different. Among cultivars, genotype explained $95 \%$ of the variation associated with gluc-ANC conjugates but only $43 \%$ and $22 \%$ of the variation associated with gala-ANC and arabANC, respectively. Although not as extreme, this trend was also seen in the analysis of selections and populations. Almost all of the variation associated with acylation could be explained by genotype with $61 \%, 88 \%$, and $89 \%$ of the variation explained by this term in cultivars, selections, and populations, respectively. A significant genotype $\times$ year interaction was detected in most cases for glycosylation and acylation but was once again a relatively minor contributor to total variance. Genotype, year, and interaction were all significant sources of variance for fruit weight, fruit diameter, and percent dry matter. With the exception of the segregating populations, the year effects of these measurements exceeded the effects associated with genotype.

Anthocyanin PRofiLe. Mean concentrations of total ANC (milligrams per $100 \mathrm{~g}$ ) of blueberry commercial cultivars, breeding selections, and breeding populations for the 2 years are presented in Table 2 . All but three of the commercial cultivars and selections produced higher levels of ANC in 2011 than in 2010. The ANC means and sDs of most commercial cultivars were comparable between years but there were exceptions; 'Pamlico' had a mean of $255 \mathrm{mg} / 100 \mathrm{~g}$ and a SD of 18 in 2010 and a mean of $411 \mathrm{mg} / 100 \mathrm{~g}$ and SD of 108 in 2011. Similarly, the selections SH2B1-20:21, SH2B1-21:3, and NC 4398 produced a 2-fold increase of total ANC in the second year of analysis. This may indicate that there could be differences in how stable ANC accumulation is among commercial cultivars and selections.

REB (6×) commercial cultivars were consistently higher in total ANC than commercial SHB $(4 \times)$ in 2 years of the study with the REB cultivar Yadkin (and the SHB cultivar Pamlico in 2011) being the only exception. 'Columbus', 'Ira', 'Powderblue', and 'Premier' had consistently high levels of ANC in 2 years of the analysis and the pentaploid 'Robeson' had the lowest levels among cultivars in 2 years. On average, higher levels of total ANC were observed among SHB $(4 \times)$ breeding selections than were observed among SHB $(4 \times)$ commercial cultivars, and this was particularly true in the second year of analysis. The hexaploid selection SA-13:75 contained the lowest levels of total ANC (69 and $78 \mathrm{mg} / 100 \mathrm{~g}$ ) among cultivars, selections, or populations in 2 years of the study and the hexaploid selection NC 3961 also contained lower levels of total ANC in 2 years when compared with most commercial REB.

The mean ANC values of the breeding populations were relatively consistent between the 2 years with ranges from 212 to $539 \mathrm{mg} / 100 \mathrm{~g}$ in 2010 and 260 to $534 \mathrm{mg} / 100 \mathrm{~g}$ in 2011 . In 2 years, the population NC $1223 \times$ 'Columbus' accumulated the highest mean value of total ANC. The two lowest population means in each year contained the parent 'Arlen' ('Arlen' $\times$ 'Georgia Gem' and NC4295 × 'Arlen'). Progeny within the populations NC $1233 \times$ 'Columbus' and CHID2-14:73 $\times$ OP accumulated total ANC concentrations of $\approx 900 \mathrm{mg} / 100 \mathrm{~g}$ in 2 years of the analysis. The lowest recorded value in any population in 2 years was $100 \mathrm{mg} / 100 \mathrm{~g}$ (multiple populations).

To facilitate comparison of ANC subclasses, values (an average of 2 years) were expressed as a percentage of total ANC (Table 3). The most striking difference observed was in the relative degree of glycosylation. No SHB cultivar accumulated more than 4.4\% glucose conjugated ANC (gluc-ANC) and was not significantly different in this respect. Conversely, seven of nine REB cultivars and the pentaploid cultivar Robeson ranged from $20 \%$ to $34 \%$ of these same compounds. The remaining REB cultivars (Ira and Premier) contained $4.5 \%$ and $3.4 \%$ glucANC, respectively, and were not significantly different from SHB cultivars. Among the REB cultivars, the reduction in glucANC is accompanied by a statistically significant increase in the percentage of gala-ANC (but not arab-ANC). The same pattern can be observed by examining the gluc-ANC fraction of the clones and the mean values of the populations. The mean value of the population NC $4299 \times$ 'Ozarkblue' (both parents $4 \times$ ) had $29 \%$ gluc-ANC, whereas the population NC2873 $\times$ OP had a mean value of $5 \%$. Relatively limited amounts of acylated ANC were observed in SHB or REB cultivars with percentages ranging from non-detectable levels to no more than $8 \%$ of the total ANC profile in the berry fruit. Significantly higher levels, however, were observed in the selection SHF2B1-21:3 (16\%) and in the mean of the population NC3147 $\times$ NC4562 (23\%). The percentage of cyan-ANC, petu-ANC, and peon-ANC is significantly higher in most REB cultivars than SHB cultivars and this increase appears to be accompanied by a relative decrease in the percentage of delp-ANC. Delp-ANC levels in SHB cultivars ranged from $31 \%$ to $36 \%$, whereas this fraction constitutes between $19 \%$ and $25 \%$ in REB. Even greater variability for delpANC levels can be observed in selections, which ranged from $19 \%$ in SA-4:2 to $42.6 \%$ in SHF2B1-25:25.

Correlation among measurments. Correlation coefficients among all measured traits in the replicated blueberry commercial cultivars and breeding selections are presented in Table 4. Negative correlations were observed between total ANC content and fruit weight and diameter $(r=-0.46$ and -0.50 , respectively). Positive correlations were observed between total ANC content and percent DM and days to harvest $(r=0.57$ and 0.43 , respectively). It is interesting to note, however, that these correlations are not consistent across all subclasses of ANC. Delp-ANC concentration is not significantly correlated with any of the phenotypic measurements, whereas concentrations of cyan-ANC, petu-ANC, and peon-ANC display stronger correlations than what was observed with total ANC. For example, the correlation between total ANC and harvest date is $r=$ 0.46 , whereas the correlation for harvest date with delp-ANC is $r=-0.13$, and the correlation for the remaining aglycone fractions is $r=0.62,0.48,0.79$, and 0.53 . A strong correlation 
Table 2. Descriptive statistics for the total anthocyanin concentration (ANC), SD, and range in the blueberry commercial cultivars, breeding selections, and breeding populations evaluated in 2010 and 2011 at Salisbury, NC.

\begin{tabular}{|c|c|c|c|c|c|}
\hline & \multirow{2}{*}{$\begin{array}{c}\text { Plants } \\
\text { evaluated (no.) }\end{array}$} & \multicolumn{2}{|l|}{2010} & \multicolumn{2}{|l|}{2011} \\
\hline & & ANC [mean \pm sD $(\mathrm{mg} / 100 \mathrm{~g})]$ & Range & ANC [mean \pm sD $(\mathrm{mg} / 100 \mathrm{~g})]$ & Range \\
\hline \multicolumn{6}{|l|}{ Commercial cultivar } \\
\hline \multicolumn{6}{|c|}{ Southern highbush $(4 \times)$} \\
\hline Legacy & 6 & $255 \pm 43$ & $205-322$ & $323 \pm 50$ & $254-374$ \\
\hline Lenoir & 4 & $176 \pm 68$ & $115-241$ & $226 \pm 44$ & $172-280$ \\
\hline O’Neal & 3 & $174 \pm 61$ & $162-186$ & $282 \pm 72$ & $260-303$ \\
\hline Pamlico & 5 & $255 \pm 18$ & $228-273$ & $411 \pm 108$ & $255-515$ \\
\hline Sampson & 5 & $168 \pm 21$ & $144-185$ & $277 \pm 36$ & $241-334$ \\
\hline \multicolumn{6}{|c|}{ Rabbiteye blueberry (6×) } \\
\hline Columbus & 3 & $455 \pm 86$ & $372-543$ & $469 \pm 58$ & $408-522$ \\
\hline Ira & 6 & $445 \pm 62$ & $331-515$ & $484 \pm 74$ & $406-567$ \\
\hline Montgomery & 5 & $294 \pm 62$ & $222-376$ & $421 \pm 118$ & $228-524$ \\
\hline Yadkin & 5 & $243 \pm 32$ & $209-291$ & $287 \pm 43$ & $227-321$ \\
\hline Robeson $(5 \times)$ & 3 & $166 \pm 30$ & $164-169$ & $213 \pm 25$ & $187-238$ \\
\hline
\end{tabular}

Breeding selection (clone)

Southern highbush $(4 \times)$

NC 4263

NC 4365

NC 4385

NC 4398

NC 4900

SA-10:135

SA-4:2

SHF2B1-20:21

SHF2B1-21:3

SHF2B1-25:25

SHF2B1-25:41

$312 \pm 58$

266-408

$455 \pm 59$

393-527

$140 \pm 30$

$159 \pm 33$

121-181

$281 \pm 60$

212-321

$293 \pm 36$

$321 \pm 39$

282-361

$213 \pm 40$

$550 \pm 36$

210-217

$225 \pm 27$

514-585

$257 \pm 19$

$431 \pm 75$

195-247

$244 \pm 19$

232-283

$267 \pm 20$

224-260

$268 \pm 78$

$343 \pm 38$

336-521

$477 \pm 109$

299-368

$256 \pm 8$

$253-281$
$193-370$

$548 \pm 11$

251-262

$201 \pm 43$

137-244

$206 \pm 35$

400-555

Rabbiteye blueberry (6×)

NC 3961

SA-13:75

$228 \pm 22$

206-250

37-125

$321 \pm 46$

181-230

282-394

$351 \pm 33$

325-389

$78 \pm 7$

70-89

Breeding population (cross)

Arlen $\times$ Georgia Gem

CHID2-14:73 $\times$ OP

$212 \pm 55$

123-444

$527 \pm 170$

270-963

NC $1223 \times$ Columbus

$539 \pm 156$

194-887

$278 \pm 105$

168-501

NC $2898 \times$ G-615

NC $3147 \times$ Legacy

NC $3147 \times$ NC 4562

$281 \pm 76$

148-427

$397 \pm 85$

259-475

$270 \pm 81$

212-327

$350 \pm 59$

252-416

$\mathrm{NC} 3958 \times \mathrm{OP}$

$\mathrm{NC} 4165 \times$ OP

NC $4295 \times$ Arlen

$371 \pm 114$

$466 \pm 201$

$154-590$

266-798

$212 \pm 54$

131-353

$291 \pm 81$

$149-591$

$262 \pm 74$

121-503

NC $4299 \times$ Ozarkblue

$325 \pm 79$

269-381

NC $4302 \times$ Georgia Gem

$359 \pm 83$

257-521

NC $4302 \times$ Sunshine Blue

$224 \pm 108$

$103-515$

$301 \pm 83$

159-533

$\mathrm{NC} 4562 \times \mathrm{NC} 4179$

$258 \pm 112$

$100-613$

$\begin{array}{ll}260 \pm 61 & 129-430 \\ 531 \pm 186 & 263-914 \\ 534 \pm 134 & 271-871 \\ 305 \pm 112 & 196-545 \\ 300 \pm 76 & 100-483 \\ 484 \pm 140 & 258-691 \\ 268 \pm 63 & 223-312 \\ 460 \pm 119 & 316-601 \\ 427 \pm 125 & 174-703 \\ 421 \pm 152 & 308-708 \\ 242 \pm 72 & 135-417 \\ 346 \pm 98 & 140-687 \\ 302 \pm 75 & 123-610 \\ 328 \pm 17 & 316-340 \\ 414 \pm 98 & 292-572 \\ 291 \pm 100 & 130-547 \\ 415 \pm 120 & 210-772 \\ 325 \pm 146 & 113-785\end{array}$


Table 2. Continued.

\begin{tabular}{|c|c|c|c|c|c|}
\hline & \multirow{2}{*}{$\begin{array}{c}\text { Plants } \\
\text { evaluated (no.) }\end{array}$} & \multicolumn{2}{|l|}{2010} & \multicolumn{2}{|l|}{2011} \\
\hline & & $\mathrm{ANC}[\mathrm{mean} \pm \mathrm{sD}(\mathrm{mg} / 100 \mathrm{~g})]$ & Range & $\mathrm{ANC}[$ mean $\pm \mathrm{sD}(\mathrm{mg} / 100 \mathrm{~g})]$ & Range \\
\hline $\mathrm{NC} 4812 \times \mathrm{OP}$ & 33 & $389 \pm 127$ & $183-721$ & $456 \pm 135$ & $193-864$ \\
\hline NC 81-10-2 × Columbus & 69 & $378 \pm 88$ & $233-579$ & $448 \pm 112$ & 255-917 \\
\hline Reveille $\times$ NC 3476 & 55 & $224 \pm 77$ & $112-429$ & $274 \pm 95$ & $124-557$ \\
\hline Reveille $\times$ NC 3920 & 6 & $313 \pm 122$ & $116-426$ & $397 \pm 97$ & $261-494$ \\
\hline
\end{tabular}

${ }^{\mathrm{z}}$ Number of blueberry plants evaluated for ANC and fruit characteristics in both years.

was observed between levels of arab-ANC and gala-ANC $(r=$ 0.90 ) but non-significant correlations were observed between levels of gluc-ANC and either arab-ANC or gala-ANC $(r=0.14$ and -0.01 , respectively). No significant correlation was observed between ANC acylation and any recorded observation.

\section{Discussion}

Interspecific hybridization in blueberry has been used for decades to develop cultivars with lower chilling requirements, better adaptation to warmer climates, and increased host plant resistance to insects and diseases (Ballington, 2009; Brevis et al., 2008; Chavez and Lyrene, 2009, 2010; Ehlenfeldt and Ballington, 2012). Issues associated with self-incompatibility and severe inbreeding depression, however, make successive cycles of backcrossing or recombinant selection impractical with blueberry, and therefore cultivars are likely to contain significant genomic complements from wild species. Traditional SHB cultivars such as Arlen or Ozarkblue were developed by introgressing (primarily) $V$. virgatum and $V$ darrowii into SHB backgrounds. Increasingly, however, breeders are expanding the gene pool of SHB by introducing introgressions from $V$. elliottii, $V$. myrsinites, $V$. pallidum, $V$. tenellum, $V$. fuscatum, $V$. constablaei, $V$. arboreum, and other species of the secondary gene pool. This study allowed us to compare the ANC profiles of current SHB and REB cultivars to selections and populations that represent a broader gene pool that results from the use of these species (see Appendix A for pedigree information).

Three distinct differences were observed between commercial SHB and the breeding selections and populations analyzed in this study. First, the total ANC content of many SHB breeding selections with introgressions from wild species was significantly higher than commercial SHB and approached the levels of what was observed in REB. Progeny within a number of the populations suggests that there is considerable genetic variation associated with total ANC content in Vaccinium species and the potential exists to develop blueberry cultivars with levels 2-fold greater than even the highest performing REB cultivars. A recent publication from the New Zealand Plant and Food Research Institute (PFR) suggested that "selection based on critical agronomic traits, such as yield, or fruit size, but not including ANC content, tends towards a marked reduction in this trait" (Stevenson and Scalzo, 2012). We found this to be the case with the hexaploid REB selections within the NCSU breeding program (which were significantly lower than hexaploid cultivars) but not the case with the tetraploid SHB selections. Eight of 11 tetraploid selections within the NC breeding program produced higher levels of ANC than currently grown SHB cultivars, and because this represents a broader gene pool through the inclusion of additional species, it is likely a result of broader introgression. The previously cited publication from PFR provides a comprehensive review of ANC surveys as well as analysis of the blueberry grown in New Zealand. The analysis conducted of New Zealand-grown REB cultivars Tifblue and Powderblue (total $\mathrm{ANC}=145$ and $165 \mathrm{mg} / 100 \mathrm{~g}$, respectively) is 2- to 3-fold lower than our estimates and the values of the SHB cultivars O'Neal and Ozarkblue are also considerably lower. In general, our results are markedly higher than previous reports of the same cultivars and this is likely attributable to environmental and cultural differences. Because the native range of most of the Vaccinium species discussed in this article includes $\mathrm{NC}$, it is not surprising they perform differently in suboptimal (non-native) environments.

Second, although commercial SHB and REB cultivars contain relatively limited amounts of acylated ANC, one of the breeding selections and one of the populations contained significantly higher levels. Acylated ANC in cabbage (Brassica oleracea $\mathrm{L}$. var. capitata $\mathrm{L}$.) and other commodities are reported to have greater color retention and overall stability (a characteristic of interest to food processors), but acylated ANC are also recovered at considerably lower levels in the blood serum or urine, which is indicative of poor absorption and bioavailability (Charron et al., 2009; He et al., 2010; Kurilich et al., 2005; Prior and Wu., 2006). In grape (Vitis vinifera L.), the biosynthesis of the acylated ANC is regulated by a single ANC acyltransferase (He et al., 2010) and the results of this current study suggest variation of acylation in blueberry is primarily genetic in nature. The occurrence of increased acylation would at face value appear to be a positive trait, because it could lead to cultivars with increased color retention and stability, but if it also leads to reduced health benefits associated with berry consumption; breeders need to be aware of the potential consequences associated with this occurrence. Both the population NC $3147 \times \mathrm{NC} 4562$ and the selection SHF2B1-21:3 contain introgressions from the wild species V. tenellum ( $5 \%$ and $7.5 \%$, respectively), but further work will be required to determine if this species was the donor of an acyltransferase associated with increased ANC acylation. Conversely, in the only known study of ANC profiles of native SHB species, Ballington et al. (1987) did not identify acylated ANC but reported a number of unknown peaks with longer retention times that likely correspond to what we have identified as acylated ANC. Accessions of the wild SHB species identified in this publication (V. elliottii, V. pallidum, $V$. tenellum, and others) contained less than $5 \%$ of these compounds, but older SHB cultivars such as Wolcott and Spartan contained up $17 \%$ of these unidentified compounds. Acylation of ANC is reported as common in LBB (Kalt et al., 2001); therefore, perhaps the acylation we are observing is not a consequence of new introgression but rather a remnant from 
Table 3. Mean concentrations of anthocyanins (ANC) and percentages of anthocyanin subclasses in the blueberry commercial cultivars, breeding selections, and breeding populations evaluated in 2010 and 2011 at Salisbury, NC.

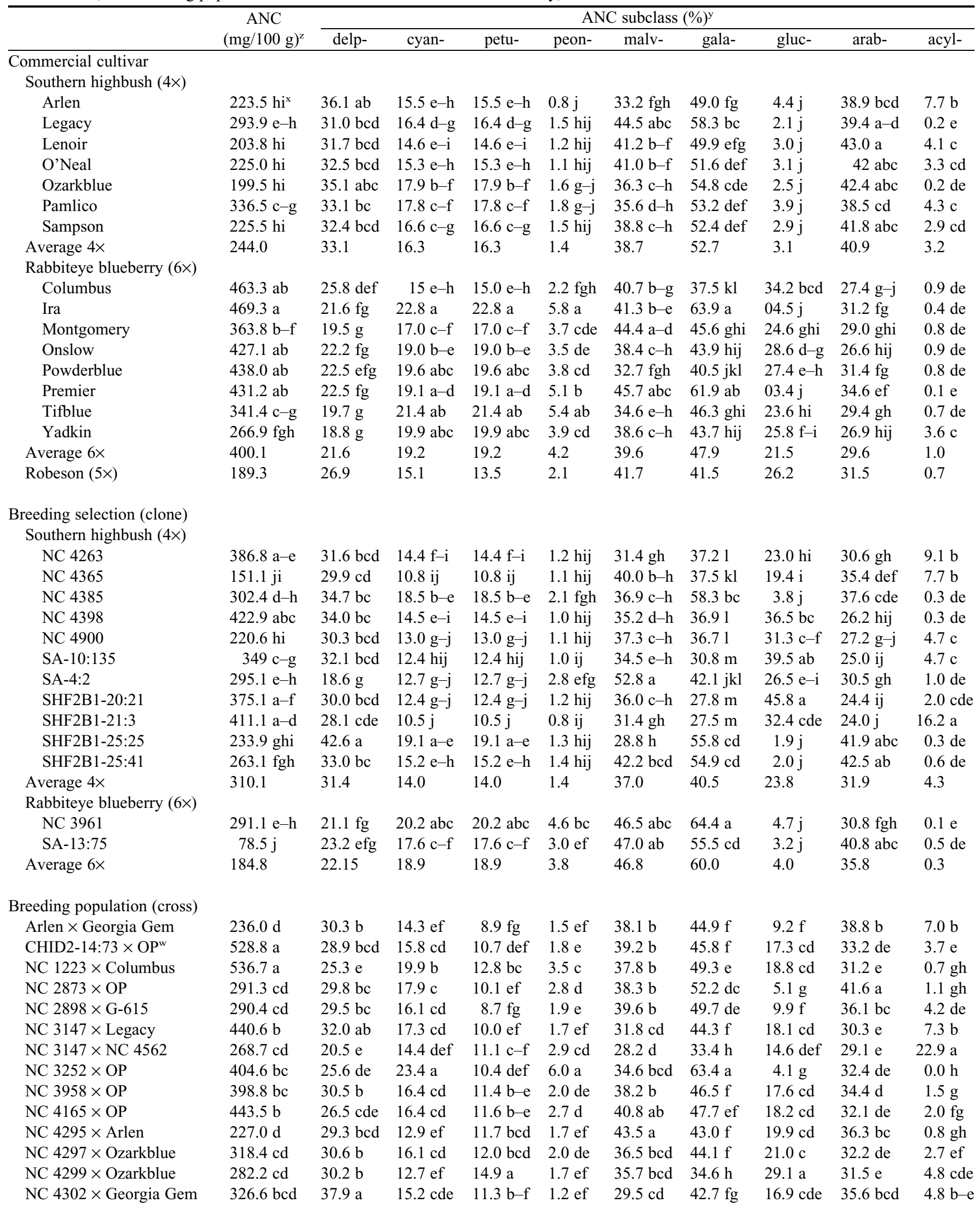


Table 3. Continued.

\begin{tabular}{|c|c|c|c|c|c|c|c|c|c|c|}
\hline & \multirow{2}{*}{$\begin{array}{c}\text { ANC } \\
(\mathrm{mg} / 100 \mathrm{~g})^{\mathrm{z}}\end{array}$} & \multicolumn{9}{|c|}{ ANC subclass $(\%)^{\mathrm{y}}$} \\
\hline & & delp- & cyan- & petu- & peon- & malv- & gala- & gluc- & arab- & acyl- \\
\hline NC $4302 \times$ Sunshine Blue & $386.7 \mathrm{bc}$ & $31.5 \mathrm{~b}$ & 13.8 ef & $11.4 \mathrm{~b}-\mathrm{e}$ & $1.5 \mathrm{ef}$ & $37.3 \mathrm{bc}$ & $42.8 \mathrm{f}$ & $19.8 \mathrm{~cd}$ & $32.9 \mathrm{de}$ & $4.5 \mathrm{cde}$ \\
\hline $\mathrm{NC} 4562 \times \mathrm{NC} 3476$ & $257.6 \mathrm{~d}$ & $29.9 \mathrm{~b}$ & $17.0 \mathrm{~cd}$ & $8.1 \mathrm{~g}$ & $2.2 \mathrm{de}$ & $39.8 \mathrm{~b}$ & $53.6 \mathrm{c}$ & $5.0 \mathrm{~g}$ & $38.4 \mathrm{~b}$ & $3.1 \mathrm{ef}$ \\
\hline $\mathrm{NC} 4562 \times \mathrm{NC} 4179$ & $358.0 \mathrm{bc}$ & $25.4 \mathrm{e}$ & $19.8 \mathrm{~b}$ & $9.9 \mathrm{f}$ & $4.3 \mathrm{~b}$ & $38.3 \mathrm{~b}$ & $56.8 \mathrm{~b}$ & $5.4 \mathrm{~g}$ & $35.5 \mathrm{~cd}$ & $2.3 \mathrm{f}$ \\
\hline $\mathrm{NC} 4562 \times \mathrm{NC} 4361$ & $291.4 \mathrm{~cd}$ & $30.8 \mathrm{~b}$ & $17.4 \mathrm{~cd}$ & $9.8 \mathrm{f}$ & $2.0 \mathrm{de}$ & $34.5 \mathrm{~cd}$ & $48.2 \mathrm{e}$ & $11.0 \mathrm{ef}$ & $35.5 \mathrm{~cd}$ & $5.3 \mathrm{bc}$ \\
\hline $\mathrm{NC} 4812 \times \mathrm{OP}$ & $422.4 \mathrm{~b}$ & $29.6 \mathrm{bc}$ & 14.0 ef & $13.4 \mathrm{bc}$ & $1.6 \mathrm{ef}$ & $37.0 \mathrm{bc}$ & $39.1 \mathrm{~g}$ & $26.2 \mathrm{~b}$ & $30.3 \mathrm{e}$ & $4.4 \mathrm{de}$ \\
\hline Reveille $\times$ NC 3476 & $248.7 \mathrm{~d}$ & $29.1 \mathrm{bcd}$ & $14.6 \mathrm{de}$ & $9.8 \mathrm{f}$ & $1.8 \mathrm{e}$ & $39.9 \mathrm{~b}$ & $45.4 \mathrm{f}$ & $11.8 \mathrm{ef}$ & $37.9 \mathrm{~b}$ & $4.9 \mathrm{bcc}$ \\
\hline Reveille $\times$ NC 3920 & $355.2 \mathrm{bc}$ & $29.4 \mathrm{bcd}$ & $11.4 \mathrm{f}$ & $14.4 \mathrm{ab}$ & $1.2 \mathrm{f}$ & $36.7 \mathrm{bcd}$ & $32.2 \mathrm{~h}$ & $28.8 \mathrm{ab}$ & $32.1 \mathrm{de}$ & $6.9 \mathrm{~b}$ \\
\hline
\end{tabular}

${ }^{\mathrm{z}}$ Total ANC (milligrams per $100 \mathrm{~g}$ frozen fruit), average of 2 years.

${ }^{y}$ Percentages of the total ANC in frozen fruit, average of 2 years; delp-, cyan-, petu-, peon-, malv-, gala-, gluc-, arab-, and acyl- refer to ANC subclasses of delphinidin-, cyanidin-, petunidin-, peonidin-, malvidin-, galactose-, glucose-, arabinose-, and acylate-based ANC subclasses, respectively.

${ }^{x}$ Means with different letters within column and group are significantly different based on Tukey's honest significant test at $P \leq 0.05$ level. Commercial cultivars and breeding selections were treated as one group of genotypes for mean separation analysis. Breeding populations were treated as one group of genotypes for mean separation analysis.

${ }^{\mathrm{w}}$ Open pollination.

the early domestication of blueberry that often involved crosses between $V$. corymbosum and $V$. angustifolium.

Third, we observed that glucose is conjugated to ANC aglycones at significantly higher levels in REB cultivars (with the exceptions of 'Ira' and 'Premier') than in the commercial SHB cultivars. However, among the $4 \times$ breeding selections, five lines produced the same glycosylation pattern and all five lines contained significant introgressions from REB. It is possible that this glycosylation pattern may have arisen from multiple sources. This same pattern of glycosylation has been observed in crosses between diploid cranberry species Vaccinium macrocarpon Ait. and $V$. oxycoccos L. (Vorsa and Polashock, 2005) and was attributed to allelic differences in a putative UDP-glucose: flavonoid-3-O-glucosyltranserfase. The biological significance of this glycosylation pattern on plant physiology or human health (through increased ANC absorption, bioavailability, or bioactivity) is still not well understood (McGhie and Walton, 2007), but the occurrence of this glycosylation pattern in both diploid (V. oxycoccos) and hexaploid (V. macrocarpon) species suggests it may be found throughout the genus.

In blueberry (to the best of our knowledge), direct selection for specific ANC profiles has not been a priority in any public or private breeding program despite increasing evidence from nutritional and medical research linking ANC content in

Table 4. Pearson's correlation coefficients among total anthocyanins (ANC), anthocyanin subclasses, fruit characteristics, and harvest date for the blueberry commercial cultivars and breeding selections evaluated in 2010 and 2011 at Salisbury, NC.

\begin{tabular}{|c|c|c|c|c|c|c|c|c|c|c|c|c|c|}
\hline \multicolumn{10}{|c|}{ ANC subclass ${ }^{z}$} & \multicolumn{3}{|c|}{ Fruit characteristic } & \multirow[b]{2}{*}{ Hdate $^{v}$} \\
\hline & delp- & cyan- & petu- & peon- & malv- & gala- & gluc- & arab- & acyl- & $\mathrm{Fwt}^{\mathrm{y}}$ & $\mathrm{Fdm}^{\mathrm{x}}$ & $\mathrm{DM}^{\mathrm{w}}$ & \\
\hline Total $\mathrm{ANC}^{\mathrm{u}}$ & $0.79 * * \mathrm{t}$ & $0.86^{* *}$ & $0.80 * *$ & $0.66^{* *}$ & $0.92 * *$ & $0.75^{* *}$ & $0.63 * *$ & $0.82 * *$ & 0.17 & $-0.46^{*}$ & $-0.50^{* *}$ & $0.57^{* *}$ & $0.43^{*}$ \\
\hline delp- & & $0.56^{* *}$ & $0.56^{* *}$ & 0.17 & $0.59^{* *}$ & $0.51 * *$ & $0.50 * *$ & $0.74 * *$ & 0.28 & -0.18 & -0.19 & 0.15 & -0.13 \\
\hline petu- & & & & $0.44^{*}$ & $0.65^{* *}$ & 0.30 & $0.90 * *$ & $0.43^{*}$ & 0.17 & $-0.52 * *$ & $-0.53 * *$ & $0.58 * *$ & $0.48 * *$ \\
\hline peon- & & & & & $0.73 * *$ & $0.84 * *$ & 0.11 & $0.63 * *$ & -0.24 & $-0.50 * *$ & $-0.61 * *$ & $0.70 * *$ & $0.79 * *$ \\
\hline malv- & & & & & & $0.81 * *$ & $0.49 * *$ & $0.79 * *$ & -0.05 & -0.36 & $-0.41 *$ & $0.54 * *$ & $0.53 * *$ \\
\hline gluc- & & & & & & & & 0.14 & 0.32 & $-0.40^{*}$ & -0.33 & $0.41 *$ & 0.26 \\
\hline arab- & & & & & & & & & -0.05 & -0.22 & -0.31 & 0.32 & 0.24 \\
\hline acyl- & & & & & & & & & & -0.16 & -0.08 & 0.02 & -0.25 \\
\hline Fwt & & & & & & & & & & & $0.95^{* *}$ & $-0.77 * *$ & $-0.44 *$ \\
\hline Fdm & & & & & & & & & & & & $-0.77 * *$ & $-0.52 * *$ \\
\hline DM & & & & & & & & & & & & & $0.64 * *$ \\
\hline
\end{tabular}

zdelp-, cyan-, petu-, peon-, malv-, gala-, gluc-, arab-, and acyl- refer to ANC subclasses of delphinidin-, cyanidin-, petonidin-, peonidin-, malvidin-, galactose -, glucose-, arabinose-, and acylate-based ANC in frozen fruit, respectively. Absolute ANC concentrations (milligrams per $100 \mathrm{~g}$ frozen fruit) were used to estimate correlation coefficients $(r)$.

${ }^{y}$ Frozen fruit weight (grams).

${ }^{x}$ Frozen fruit diameter (millimeters).

wDry matter content (percent) in fruit.

vHarvest date.

"Total ANC in frozen fruit.

${ }^{\mathrm{t}}$ Correlation coefficients with $*$ and $* *$ are significantly different at $P \leq 0.05$ and $P \leq 0.01$, respectively. 


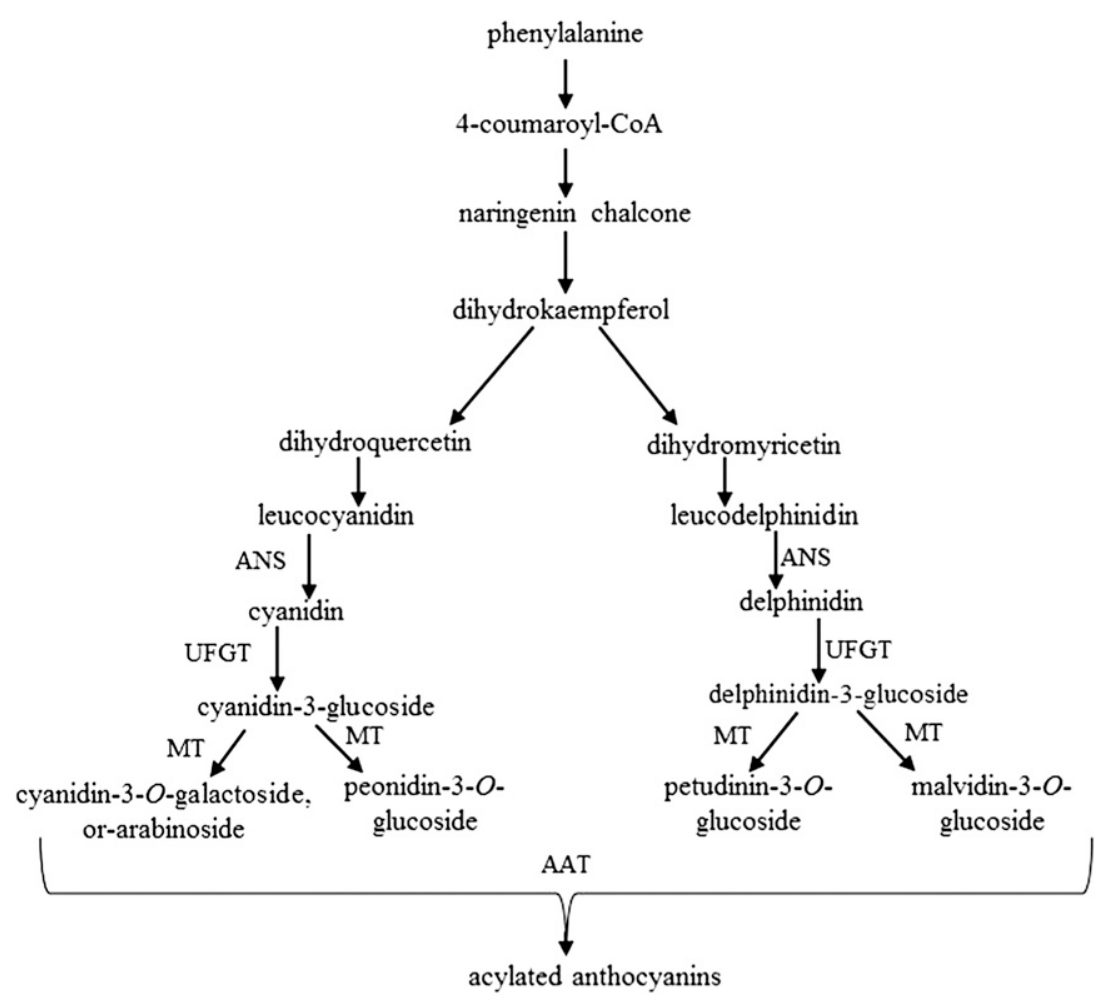

Fig. 2. A simplified schematic presentation of the anthocyanin biosynthetic pathway (He et al., 2010; Jakola et al., 2002); ANS = anthocyanidin synthase; UFGT = UDP Glc-flavonoid 3-O-glycosyl transferase; $\mathrm{MT}=$ methyl transferase; $\mathrm{AAT}=$ anthocyanin acyltransferase.

correlations with the same traits. Plants accumulate ANC through the delphinidin or cyanidin aglycone biosynthetic pathways (Fig. 2). The enzymatic production of stable ANC from the substrates dihydromyricetin and dihydroquercetin is thought to be catalyzed by the same four enzymes but allelic variation and/or substrate specificity of these enzymes is certainly a possibility. Taken together these observations support a model of genetic control of ANC accumulation in blueberry that likely includes both quantitative (overall accumulation of ANC) and qualitative (accumulation of specific ANC) factors.

\section{Literature Cited}

Ballington, J.R. 2001. Collection, utilization, and preservation of genetic resources in Vaccinium. HortScience 36:213-220.

Ballington, J.R. 2009. The role of interspecific hybridization in blueberry improvement. Acta Hort. 810:49-60.

Ballington, J.R., W.E. Ballinger, and E.P. Maness. 1987. Interspecific differences in the percentage of anthocyanins, aglycones, and aglycone sugars in the fruit of seven species of blueberries. J. Amer. Soc. Hort. Sci. 112:859-864.

Ballington, J.R. and S.D. Rooks. 2009. Blueberry named 'Robeson'. USPP 19756 P3. U.S. Patent Trade Mark Office, Washington, DC.

Basu, A., M. Du, M.J. Leyva, K. Sanchez, N.M. Betts, M. Wu, C.E. Aston, and T.J. Lyons. 2010.

blueberry to health. Blueberry ANC content has been directly linked to lowering blood glucose levels in diabetic mice (Grace et al., 2009; Rojo et al., 2012), improved insulin resistance (Stull et al., 2010), protection from neuropathy (Tremblay et al., 2013), and numerous additional health benefits. It could be theorized that indirect selection of ANC content has occurred, because it is likely related to both flavor and color of the blueberry fruit; however, the almost 2-fold variation that we observed among the commercial cultivars suggests ANC accumulation can vary over a relatively broad range before either of these important traits is negatively impacted.

Our study demonstrates the potential opportunities (and consequences) of introducing genes from the expanded gene pool that could increase total ANC content and (potentially) the bioavailability of these compounds by altering acylation or the glycosylation patterns. A number of lines of evidence also suggest it may be possible to select for altered ratios of ANC subclasses. First, our results suggest that REB cultivars accumulate significantly greater proportions of cyan-ANC, petu-ANC, and peon-ANC and reduced proportions of delp-ANC when compared with SHB.

Second, we observed a greater than 2-fold variation of delpANC proportions among the breeding selections ranging from $19 \%$ in SA-4:2 to $42.6 \%$ in SHF2B1-25:25. Third, the range of correlation values we observed among aglycone subclasses ranged from a high of 0.89 (between peon-ANC and cyan-ANC) to a low of 0.17 (between peon-ANC and delp-ANC). Finally (and perhaps most surprising) was the observation that delpANC in blueberry was not significantly correlated with fruit diameter, harvest date, or weight of the fruit, whereas other ANC aglycone subclasses displayed moderate but significant
Blueberries decrease cardiovascular risk factors in obese men and women with metabolic syndrome. J. Nutr. 140:1582-1587.

Blanck, H.M., C. Gillespie, J.E. Kimmons, J.D. Seymour, and M.K. Serdula. 2008. Trends in fruit and vegetable consumption among U.S. men and women, 1994-2005. Prev. Chronic Dis. 5:1-10.

Brevis, P.A., N.V. Bassil, J.R. Ballington, and J.F. Hancock. 2008. Impact of wide hybridization on highbush blueberry breeding. J. Amer. Soc. Hort. Sci. 133:427-437.

Charles, F.F., W. Kalt, M.A. Jordan, M.R. Vinqvist-Tymchuk, and S.A.E. Fillmore. 2012. Blueberry and cranberry fruit composition during development. J. Berry Res. 2:169-177.

Charron, C.S., A.C. Kurilich, B.A. Clevidence, P.W. Simon, D.J. Harrison, S.J. Britz, D.J. Baer, and J.A. Novotny. 2009. Bioavailability of anthocyanins from purple carrot juice: Effects of acylation and plant matrix. J. Agr. Food Chem. 57:1226-1230.

Chavez, D.J. and P.M. Lyrene. 2009. Interspecific crosses and backcrosses between diploid Vaccinium darrowii and tertraploid southern highbush blueberry. J. Amer. Soc. Hort. Sci. 134:273-280.

Chavez, D.J. and P.M. Lyrene. 2010. Hybridization of two diploid Vaccinium section Cyanococcus species with diploid Vaccinium arboreum in section Batodendron. Euphytica 171:263-272.

Connor, A.M., J.J. Luby, C.B.S. Tong, C.E. Finn, and J.F. Hancock. 2002. Genotypic and environmental variation in antioxidant activity, total phenolic content, and anthocyanin content among blueberry cultivars. J. Amer. Soc. Hort. Sci. 127:89-97.

Davis, D.R. 2009. Declining fruit and vegetable nutrient composition: What is the evidence? HortScience 44:15-19.

DeFuria, J., G. Bennett, K.J. Strissel, J.W. Perfield, P.E. Milbury, A.S. Greenberg, and M.S. Obin. 2009. Dietary blueberry attenuates wholebody insulin resistance in high fat-fed mice by reducing adipocyte death and its inflammatory sequelae. J. Nutr. 139:1510-1516.

Ehlenfeldt, M.K. and J.R. Ballington. 2012. Vaccinium species of section Hemimyrtillus: Their value to cultivated blueberry and approaches to utilization. Bot. 90:347-353. 
Galletta, G.J. and J.R. Ballington. 1996. Blueberries, cranberries, and lingonberries, p. 1-107. In: Janick, J. and J.N. Moore (eds.). Fruit breeding. Vol. II, Vine and small fruit crops. Prentice Hall, New York, NY.

Gonzales-Gallego, J., M.V. Garcia-Mediavilla, S. Sanchez-Campos, and M.J. Tunon. 2010. Fruit polyphenols, immunity and inflammation. Brit. J. Nutr. 104:S15-S27.

Grace, M., D. Ribnicky, P. Kuhn, A. Poulev, S. Logendra, G.G. Yousef, I. Raskin, and M.A. Lila. 2009. Hypoglycemic activity of a novel anthocyanin-rich formulation from lowbush blueberry, Vaccinium angustifolium Aiton. Phytomedicine 16:406-415.

Gustafson, S.J., G.G. Yousef, M.A. Grusak, and M.A. Lila. 2012. Effect of postharvest handling practices on phytochemical concentrations and bioactive potential in wild blueberry fruit. J. Berry Res. 2:215-227.

He, F., L. Mu, G.-L. Yan, N.-N. Liang, Q.-H. Pan, J. Wang, M.J. Reeves, and C.-Q. Duan. 2010. Biosynthesis of anthocyanins and their regulation in colored grapes. Molecules 15:9057-9091.

Jaakola, L., K. Maatta, A.M. Pirttila, R. Torronen, S. Karenlampi, and A. Hohtola. 2002. Expression of genes involved in anthocyanin biosynthesis in relation to anthocyanin, proanthocyanidin, and flavonol levels during bilberry fruit development. Plant Physiol. 130:729-739.

Johnson, M., E.G. de Mejia, J. Fan, M.A. Lila, and G.G. Yousef. 2013. Anthocyanins and proanthocyanidins from blueberry-blackberry fermented beverages inhibit markers of inflammation in macrophages and carbohydrate-utilizing enzymes in vitro. Mol. Nutr. Food Res. 57:1182-1197.

Kalt, W., S. MacKinnon, J. McDonald, M. Vinqvist, C. Craft, and A. Howell. 2008. Phenolics of Vaccinium berries and other fruit crops. J. Sci. Food Agr. 88:68-76.

Kalt, W., D.A. Ryan, J.C. Duy, R.L. Prior, M.K. Ehlenfeldt, and S.P. Vander Kloet. 2001. Interspecific variation in anthocyanins, phenolics, and antioxidant capacity among genotypes of highbush and lowbush blueberries (Vaccinium section Cyanococcus spp.). J. Agr. Food Chem. 49:4761-4767.

Kurilich, A.C., B.A. Clevidence, S.J. Britz, P.W. Simon, and J.A. Novotny. 2005. Plasma and urine responses are lower for acylated vs nonacylated anthocyanins from raw and cooked purple carrots. J. Agr. Food Chem. 53:6537-6542.

Manach, C., G. Williamson, C. Morand, A. Scalbert, and C. Remesy. 2005. Bioavailability and bioefficacy of polyphenols in human. I. Review of 97 bioavailability studies. Amer. J. Clin. Nutr. 81:230S242S.

Martineau, L.C., A. Couture, D. Spoor, A. Benhaddou-Andaloussi, C. Harris, B. Meddah, C. Leduc, A. Burt, T. Vuong, P.M. Le, M. Prentki, S.A. Bennett, J.T. Arnason, and P.S. Haddad. 2006. Antidiabetic properties of the Canadian lowbush blueberry Vaccinium angustifolium Ait. Phytomedicine 13:612-623.

McGhie, T.K. and M.C. Walton. 2007. The bioavailability and absorption of anthocyanins: Towards a better understanding. Mol. Nutr. Food Res. 51:702-713.

Prior, R., G. Cao, A. Martin, E. Sofic, J. McEwen, C. O'Brien, N. Lischner, M. Ehlenfeldt, W. Kalt, G. Krewer, and C. Mainland. 1998. Antioxidant capacity as influenced by total phenolic and anthocyanin content, maturity, and variety of Vaccinium species. J. Agr. Food Chem. 46:2686-2693.

Prior, R.L., S.A. Lazarus, G. Cao, H. Muccitelli, and J.F. Hammerstone. 2001. Identification of procyanidins and anthocyanins in blueberries and cranberries (Vaccinium spp.) using high-performance liquid chromatography/mass spectrometry. J. Agr. Food Chem. 49:12701276.

Prior, R.L. and X. Wu. 2006. Anthocyanins: Structural characteristics that result in unique metabolic patterns and biological activities. Free Radic. Res. 40:1014-1028.

Reyes-Carmona, J., G.G. Yousef, R. Martinez-Peniche, and M.A. Lila. 2005. Antioxidant capacity of fruit extracts of blackberry (Rubus spp.) produced in different climatic regions. J. Food Sci. 70:S497S503.

Rimando, A.M., W. Kalt, J.B. Magee, J. Dewey, and J.R. Ballington. 2004. Resveratrol, pterostilbene, and piceatannol in Vaccinium berries. J. Agr. Food Chem. 52:4713-4719.

Rojo, L., D. Ribnicky, S. Logendra, A. Poulev, P. Rojas-Silva, P. Kuhn, R. Dorn, M.H. Grace, M.A. Lila, and I. Raskin. 2012. In vitro and in vivo anti-diabetic effects of anthocyanins from maqui berry (Aristotelia chilensis). Food Chem. 131:387-396.

Scalzo, J., J. Stanley, P. Alspach, and B. Mezzetti. 2013. Preliminary evaluation of fruit and phytochemicals in highbush blueberry seedling population. J. Berry Res. 3:103-111.

Sharpe, R.H. 1954. Horticultural development of Florida blueberries. Proc. Florida State Hort. Soc. 66:188-190.

Spiers, J.M., C.L. Gupton, and A.D. Draper. 1996. 'Jubilee', 'Magnolia', and 'Pearl River' southern highbush blueberries. Acta Hort. 446:155-157.

Stevenson, D. and J. Scalzo. 2012. Anthocyanin composition and content of blueberries from around the world. J. Berry Res. 2:179-189.

Stringer, S.J., A.D. Draper, J.M. Spiers, D.A. Marshall, and B.J. Smith. 2013. 'Pearl' southern highbush blueberry. HortScience 48:130-131.

Stull, A.J., K.C. Cash, W.D. Johnson, C.M. Champagne, and W. Cefalu. 2010. Bioactives in blueberry improve insulin sensitivity in obese, insulin-resistant men and women. J. Nutr. 140:1764-1768.

Tremblay, F., J. Waterhouse, J. Nason, and W. Kalt. 2013. Prophylactic neuroprotection by blueberry-enriched diet in a rat model of light-induced retinopathy. J. Nutr. Biochem. 24:647-655.

Tsuda, H.T., H. Kunitake, M. Yamasaki, H. Komatsu, and K. Yoshioka. 2013. Production of intersectional hybrids between colchicine-induced tetraploid Shashanbo (Vaccinium bracteatum) and highbush blueberry 'Spartan'. J. Amer. Soc. Hort. Sci. 138:317324.

U.S. Department of Agriculture. 2013. Economic, statistics, and information system. Table D2. Blueberries: Acres, yield, production, price, by state, various years to date. 8 Dec. 2013. $<$ http://usda. mannlib.cornell.edu/MannUsda/viewDocumentInfo.do?documentID= $1377 />$.

Vorsa, N. and J.J. Polashock. 2005. Alternation of anthocyanin glycosylation in cranberry through hybridization. J. Amer. Soc. Hort. Sci. 130:711-715.

Wang, S.Y., H. Chen, M.J. Camp, and M.K. Ehlenfeldt. 2012. Flavonoid constituents and their contribution to antioxidant activity in cultivars and hybrids of rabbiteye blueberry (Vaccinium ashi Reade). Food Chem. 132:855-864.

Yi, W., C.C. Akoh, J. Fisher, and G. Krewer. 2006. Absorption of anthocyanins from blueberry extracts by caco-2 human intestinal cell monolayers. J. Agr. Food Chem. 54:5651-5658.

Yousef, G.G., A.F. Brown, Y.F. Funakoshi, F.M. Mbeunkui, M.H. Grace, J.R. Ballington, A. Loraine, and M.A. Lila. 2013. Efficient quantification of the heath-relevant anthocyanin and phenolic acid profiles in commercial cultivars and breeding selections of blueberries (Vaccinium spp.). J. Agr. Food Chem. 61:4806-4815. 
Appendix A. Pedigree and ploidy levels for blueberry commercial cultivars, breeding selections, and breeding populations evaluated for anthocyanins and fruit characteristics in 2010 and 2011 at Salisbury, NC.

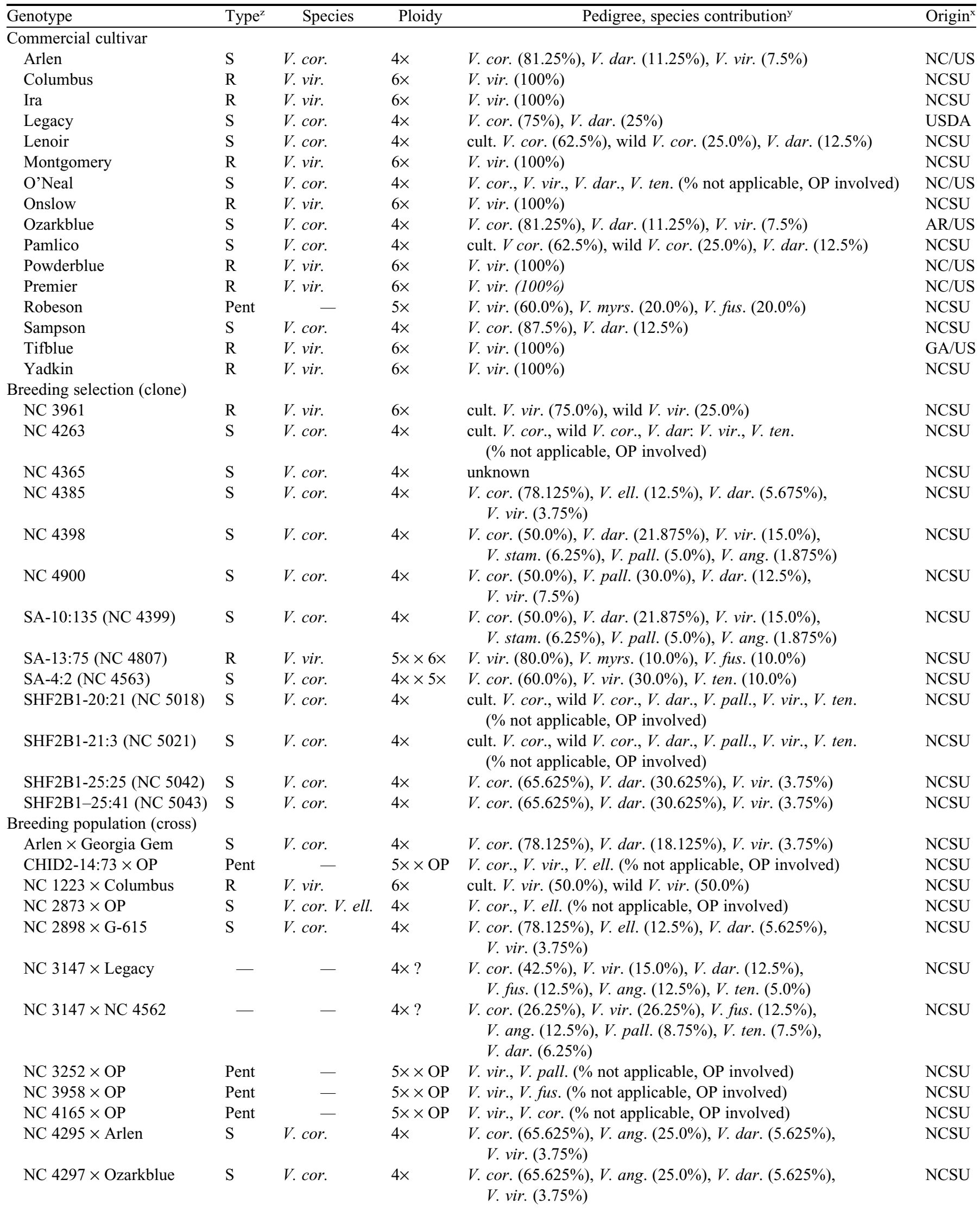


Appendix A. Continued.

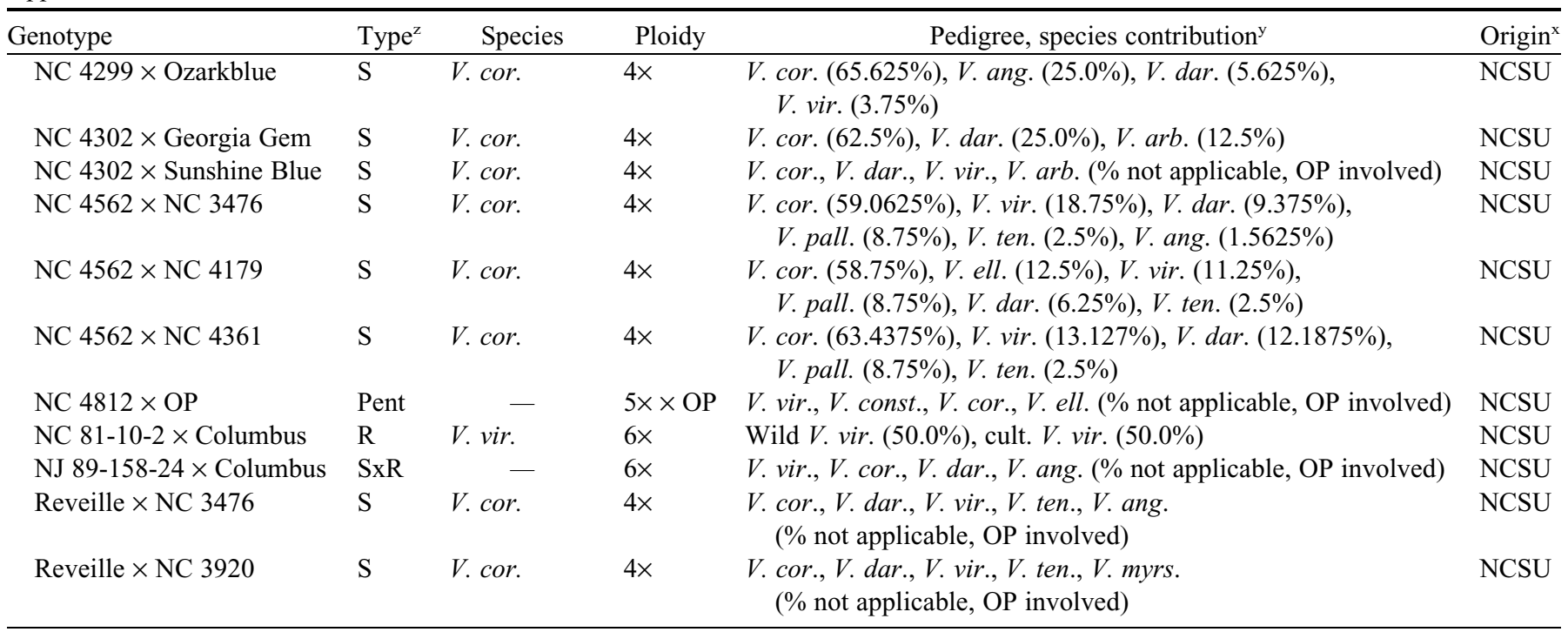

${ }^{\mathrm{z}} \mathrm{S}=$ southern highbush blueberry; $\mathrm{R}=$ rabbiteye blueberry; Pent $=$ pentaploid blueberry.

${ }^{\mathrm{y}} V$. cor. $=$ Vaccinium corymbosum $;$. dar. $=V$. darrowii $; V$. vir. $=V$. virgatum (previously $V$. ashei); V. ang. =V. angustifolium; V. ell. $=V$.

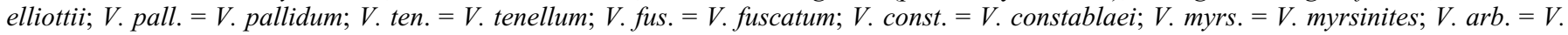
arboreum; cult. $=$ cultivated; $\mathrm{OP}=$ open pollination .

${ }^{\mathrm{x} C}=$ North Carolina; US = United States; NCSU = North Carolina State University; USDA = U.S. Department of Agriculture; AR = Arkansas; $\mathrm{GA}=$ Georgia. 